\title{
Morphology, adipocyte size, and fatty acid analysis of dairy cattle digital cushions, and the effect of body condition score and age
}

\author{
R. F. Newsome, ${ }^{1 *} \odot$ A. Mostyn,,${ }^{1,2} \odot$ J. P. Wilson, ${ }^{1}$ A. Alibhai, ${ }^{1}$ N. Bollard, ${ }^{1} \odot$ L. Randall, ${ }^{1}$ M. G. G. Chagunda, ${ }^{3} \odot$ \\ C. J. Sturrock, ${ }^{4}$ M. Keane, ${ }^{1} \odot M$ M. Green, ${ }^{1} \odot$ J. N. Huxley, ${ }^{5} \odot$ and C. S. Rutland ${ }^{1} \dagger \oplus$ \\ ${ }^{1}$ School of Veterinary Medicine and Science, University of Nottingham, Sutton Bonington Campus, Sutton Bonington, Leicestershire, LE12 5RD, \\ United Kingdom \\ ${ }^{2}$ School of Health Sciences, University of Nottingham, Queen's Medical Centre, Nottingham NG7 2UH, United Kingdom \\ ${ }^{3}$ Scotland's Rural College, Kings Buildings, West Mains Road, Edinburgh, EH9 3JG, United Kingdom, and Department of Animal Breeding \\ and Husbandry in the Tropics and Subtropics, University of Hohenheim, 70599 Stuttgart, Germany \\ ${ }^{4}$ Hounsfield Facility, School of Biosciences, University of Nottingham, LE12 5RD, United Kingdom \\ ${ }^{5}$ School of Veterinary Science, Massey University, Private Bag 11-222, Palmerston North, New Zealand
}

\section{ABSTRACT}

The digital cushion is an essential part of maintaining a healthy foot, working to dissipate foot strike and body weight forces and lameness from claw horn disruption lesions. Despite the importance of the digital cushion, little is known about the basic anatomy, adipocyte morphology, and fatty acid composition in relation to age, limb position, and body condition score. In total, 60 claws (from 17 cows) were selected and collected from a herd, ensuring that body condition score data and computed micro-tomography were known for each animal. Digital cushion tissue underwent histological staining combined with stereology, systematic random sampling, and cell morphology analysis, in addition to lipid extraction followed by fatty acid analysis. The results describe digital cushion architecture and adipocyte sizes. Adipocyte size was similar across all 4 claws (distal left lateral and medial and distal right lateral and medial) and across the ages (aged 2-7 yr); however, animals with body condition score of 3.00 or more at slaughter had a significantly increased cell size in comparison to those with a score of less than 2.50. Of 37 fatty acid methyl esters identified, 5 differed between either the body condition score or different age groups. C10:0 capric acid, C14:0 myristic acid, C15:0 pentadecanoic acid, and C20:0 arachidic acid percentages were all lesser in lower body condition score cows, whereas C22:1n-9 erucic acid measurements were lesser in younger cows. Saturated fatty acid, monounsaturated fatty acid, and polyunsaturated fatty acid percentages were not altered in the different claws, ages, or body

Received July 30, 2020.

Accepted January 21, 2021.

*Present address: Park Vet Group, 82-84 High Street, Whetstone, Leicestershire, LE8 6LQ, United Kingdom.

†Corresponding author: catrin.rutland@nottingham.ac.uk condition score groups. Triglyceride quantities did not differ for claw position or age but had decreased quantities in lower body condition score animals. Digital cushion anatomy, cellular morphology, and fatty acid composition have been described in general and also in animals with differing ages, body condition scores, and in the differing claws. Understanding fat deposition, mobilization, and composition are essential in not only understanding the roles that the digital cushion plays but also in preventing disorders and maintaining cattle health and welfare.

Key words: adipocyte, body condition score, bovine lameness, digital cushion, fatty acid

\section{INTRODUCTION}

The digital cushion is a key component of the supportive apparatus in the bovine foot (Räber et al., 2004). It is a modification of the subcutis layer of the integument and is thought to dissipate ground reaction forces during foot strike and loading into the structures that are designed to bear weight, and reduce peak loads on the germinal epithelium of the sole (Dietz and Heyden, 1990; Lischer et al., 2002; Räber et al., 2004). Such a function would render it vital in preventing claw horn disruption lesions (CHDL: sole ulcer, sole hemorrhage, and white line disease), as these lesions form as a result of excessive pressure on the sole soft tissues which in turn can affect the digital cushion, dermis, suspensory apparatus, vascular system, dermal-epidermal junction, and the germinal epithelium producing horn (Bicalho and Oikonomou, 2013; Newsome et al., 2017a,b).

The digital cushion (Figures 1 and 2) is composed of connective tissue, containing 3 loosely defined cylindrical parallel fat depots. The pads are situated in the heel, parallel to the deep digital flexor tendon, and extend dorsally beneath the plantar two-thirds of the flexor tuberosity of the distal phalanx (Lischer et al., 


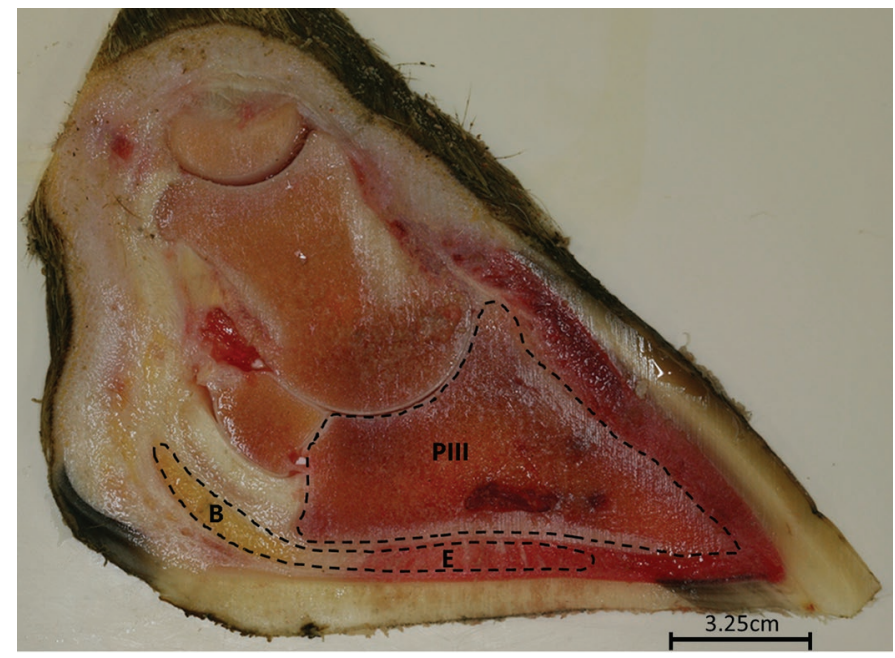

Figure 1. Prosection of a bovine claw, with the distal phalanx (PIII) and the digital cushion outlined. Two areas of the digital cushion are marked, B and E, which are the locations described by Räber et al. (2006) in a study of the biochemical composition of the digital cushion.

2002; Räber et al., 2004). The digital cushion differs in structure and composition to other fat depots, perhaps to optimize shock dissipation and absorption. For example, the cushion has a lesser total lipid content (37 $\mathrm{g}$ vs. $87-94 \mathrm{~g} / 100 \mathrm{~g}$ of tissue) than perirenal adipose tissue (Casutt et al., 1999; Räber et al., 2006). Further, differences occur with cow-level variables, such as age; the digital cushions of parity $\geq 2$ animals have been reported as having greater lipid content than parity 1 animals and higher concentrations of MUFA (averaging more than $77 \%$ ), in comparison with perirenal and subcutaneous adipose tissue at $32 \%$ and $54 \%$, respectively (Baird et al., 2010); this has led to the hypothesis that the digital cushion may not be fully developed in first lactation.

Several epidemiological studies have linked low BCS and BCS loss with greater risk of CHDL (Green, 2014; Lim, 2015; Randall, 2015). One proposed explanation is that there is a positive correlation between BCS and thickness of the digital cushion, so fat might be mobilized from the digital cushion, resulting in decreased biomechanical function. This association has been reported both in cross-sectional studies, whereby thinner cows had thinner digital cushions (Bicalho et al. 2009; Stambuk et al., 2020), and in a longitudinal study, whereby thickness of the digital cushion was associated with BCS over time (Newsome et al., 2017a). Both data sets showed cows with thin digital cushions to be at higher risk of CHDL (Machado et al., 2011; Newsome et al., 2017b), and the absolute thinness of the digital cushion, rather than the degree of reduction in thick- ness, appeared to be the best predictor of lameness (Newsome et al., 2017b). Digital cushion thickness also varies by breed and age, and cows have been shown to have had a thicker cushion before calving than in mid lactation (Stambuk et al., 2020). The same study found the front medial digit to have the thickest digital cushion, whereas the hind medial digit had the thinnest.

The basic anatomy of the digital cushion has been described in cattle (Räber et al., 2004, 2006); however, little is known about the detailed cellular morphology and fatty acid composition. Studies to evaluate the associations between cow age and BCS with digital cushion morphology, adipocyte structure, and fat composition have not been undertaken. The aims of this work were to (1) provide morphological descriptions of the digital cushion and provide stereological data on adipocyte size, (2) determine whether adipocyte cell size was associated with BCS at slaughter, and (3) to explore the fatty acid composition of the digital cushions from various locations in the claw relative to BCS and age.

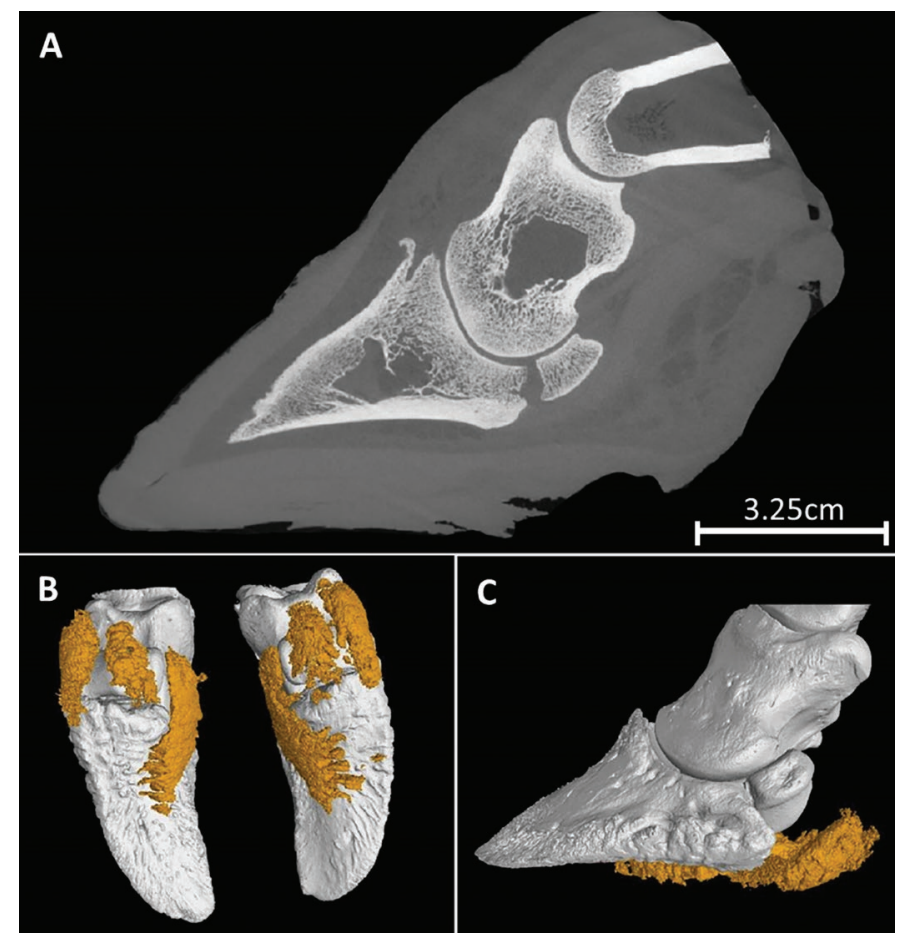

Figure 2. Computed micro-tomography images illustrating bones and fat deposits within the bovine foot. (A) A mid-sagittal section through a claw, similar to the prosection displayed in Figure 1. (B and C) Three-dimensional graphics displaying the bones (white) and fat depots (yellow) within the digital cushion, viewed from plantar and abaxial perspectives, respectively. Constructed using VGStudio Max 2.2 Software (Volume Graphics $\mathrm{GmbH}$ ) with rendering thresholds applied for bone and lipids; the scans were optimized for bone, and therefore the yellow-shaded areas picturing the fat depots within the digital cushions are for illustrative purposes only and do not represent the true volume of fat that they contain. 


\section{MATERIALS AND METHODS}

\section{Sample Collection and Ethics}

Ethical approval was given by the University of Nottingham, School of Veterinary Medicine and Science ethics committee. The distal limbs of Holstein cows that were raised at Scotland's Rural College (SRUC) Dairy Research and Innovation Centre in the Langhill herd at the Crichton Royal Farm were collected postslaughter from the abattoir as previously described (Newsome et al., 2016). Feet were transported to University of Nottingham on ice and stored at $-20^{\circ} \mathrm{C}$ before thawing for histology, computed micro-tomography, and fatty acid analysis. Animals in the Langhill herd were managed on a long-term $2 \times 2$ factorial trial, in which animals could belong to 1 of 2 management systems (homegrown or by-product) and 1 of 2 genetic lines (control or select). The selection criteria for the genetic line was based on the sire's predicted transmitting abilities for milk butterfat and protein (Pryce et al., 1999). Data collection protocols dictated that animals had BCS recorded on a weekly basis by a trained and experienced technician utilizing the BCS system as previously described (Mulvany, 1977), on a 1 to 5 scale using 0.25 increments.

From this collection, feet were selected if they met the following criteria: (1) locomotion score data were available immediately preceding slaughter, (2) had been housed and fed according to 1 of 2 management systems (homegrown or by-product), as described previously (Newsome et al., 2016), for the majority of their life since first calving, and (3) had undergone computed micro-tomography (Keane et al., 2016) and bone development on the distal phalanx of each claw had been measured. The computed micro-tomography images also aided tissue dissection (Figure 2; protocol for computed micro-tomography described previously; Newsome et al., 2016). The cows had been culled within their first 4 lactations, genetic line (control or select) was known, as was feed management system (homegrown or by-product), and cows were selected if they had a BCS determined within $7 \mathrm{~d}$ preceding slaughter. A subset of 17 cows, with 60 claws collected after slaughter, met the inclusion criteria. Other data available on the cows included age, lameness history, and bone development on the flexor tuberosity of the distal phalanx in multiple directions, as described previously (Newsome et al., 2016). Work was carried out with ethical permission following institutional and national guidelines.

\section{Histological Preparation and Staining}

Cuboidal digital cushion tissue samples were dissected from the middle pad beneath the distal phalanx
(Figure 1, site E), as described by Räber (Mayhew and Burton, 1988). To ensure appropriate orientation of the tissue for histology, pieces were cut very specifically. The dimensions of the cuboid were classified as width from axial to abaxial, length from dorsal to cranial, and height vertically. Width was always the greatest dimension, followed by length, and height was the smallest dimension; this ensured that the tissue could be orientated and sectioned in the frontal plane. Samples were washed twice in $1 \times$ PBS for 10 min under constant agitation. An optimized fixation protocol (following trials on tissue from one cow) was used with samples placed in PBS for $16 \mathrm{~h}$, followed by $10 \%$ neutral buffered formalin for $8 \mathrm{~h}$. For processing, samples were dehydrated in increasing concentrations of ethanol $[70 \%$ for $1.5 \mathrm{~h}$ at room temperature, $90 \%$ for $72 \mathrm{~h}$ at $5^{\circ} \mathrm{C}, 100 \%$ for $3 \mathrm{~h}$ at room temperature $(\times$ $2)$ ], immersed in xylene for $3 \mathrm{~h}(\times 2)$, and embedded in paraffin wax at $60^{\circ} \mathrm{C}$. Tissue sections were cut in the sagittal plane at $9 \mu \mathrm{m}$ using a microtome [Leica Microsystems (UK) Ltd.] with a N35 long duration stainless steel microtome blade (FEATHER) and mounted onto polysilinated glass microscope slides (Fisher Scientific Ltd.). The sections were then stained with hematoxylin and eosin. Sections were deparaffinized in xylene for 4 min, rehydrated through an ethanol series $(100 \%$, $90 \%$, then $70 \%$; 4 min each), rinsed with distilled water $\left(\mathbf{d H}_{2} \mathbf{O}\right)$, placed into hematoxylin (Sigma-Aldrich) for 2.5 min, and rinsed again with $\mathrm{dH}_{2} \mathrm{O}$. The sections were then immersed in $1 \%$ industrial methylated spirit and $10 \%$ ammoniated water for $15 \mathrm{~s}$ each, rinsed, and then placed in eosin (Sigma-Aldrich) for $4 \mathrm{~min}$ and rinsed in $\mathrm{dH}_{2} \mathrm{O}$. The sections were then dehydrated through an ethanol series $(70 \%, 90 \%$, and $100 \%$; 4 min each), placed in xylene for $4 \mathrm{~min}$, and mounted with DPX mountant and a glass coverslip.

\section{Stereology and Systematic Random Sampling}

Systematic random sampling (Mayhew and Burton, 1988) was utilized to analyze histological sections. Photomicrographs were studied morphologically to describe tissue morphology. A minimum of 200 adipocytes were assessed per claw by manually measuring their circumference using ImagePro Plus (Media Cybernetics). Using systematic random sampling with 2 trained individuals, no cell was counted twice, only whole cells were measured, and each photomicrograph boundary acted as a forbidden line. The surface area of each cell was calculated by the image analysis software, from which diameter of the cell was estimated using the following equation: diameter $=2 \times \sqrt{ }($ surface area $/ \pi)$.

As with all histological data, only cells positively identified as adipocytes were measured. Cells excluded 
were those $<70 \mu \mathrm{m}^{2}$ (as the lower limit) and cells $>2,000$ $\mu \mathrm{m}^{2}$ (upper limit). Cells $<70 \mu \mathrm{m}^{2}$ could be fibroblastic preadipocytes, large (late) lipoblasts, or adipoblasts, and this therefore set the lower boundary limit. The cells $>2,000 \mu \mathrm{m}^{2}$ resulted in a subset of outliers constituting approximately $2 \%$ of all measurements, which were 10 to 100 times greater than the other $98 \%$ of cell measurements. In the cells $>2,000 \mu^{2}$, remnants of plasma membrane were observed, indicating that in fact these were originally 2 or more cells with disrupted membranes; therefore, the data were truncated and cells with broken plasma membranes were not included within the data set. The cells $<70$ and $>2,000 \mu \mathrm{m}^{2}$ were described in the morphological data and their cell sizes were recorded but were not included within the cell size data as they were not typical adipocytes. These size and membrane considerations are usually take into account when identifying adipocyte cells either manually or using detection software (Björnheden et al., 2004; Osman et al., 2013; Parlee et al., 2014).

\section{Lipid Extraction and Fatty Acid Analysis}

A section was taken from a different part of the same digital cushion for lipid analysis from the caudal aspect of the middle pad (Figure 1, site B), as previously described (Räber et al., 2006). Lipids were extracted according to a modification of the Folch et al. (1957) method, which was optimized within our laboratories (Fainberg et al., 2012). Briefly, $0.25 \mathrm{~g}$ of the sample was removed and diced finely with a scalpel, then homogenized in $2 \mathrm{~mL}$ of chloroform/methanol (2:1) solvent, on ice. The homogenate was agitated for $15 \mathrm{~min}$ at room temperature, then passed through filter paper to recover the liquid phase. The test tubes, filter paper, and funnel were then washed using $3 \mathrm{~mL}$ of solvent, then washed further with $1.5 \mathrm{~mL}$ of $\mathrm{dH}_{2} \mathrm{O}$ into the sample. Samples were mixed with a vortex for $5 \mathrm{~s}$, then centrifuged at $700 \times g$ for $10 \mathrm{~min}$ at room temperature to separate the sample into 3 phases. A Pasteur pipette was used to discard the upper phase (debris) and middle phase (gel-like interphase). The vortex, centrifuge, and removal of impurities were repeated. This gave the sample of lipids suspended in chloroform and methanol.

Samples were then methylated before undergoing GC to determine the fatty acid composition in the phospholipids. The chloroform and methanol were evaporated using a nitrogen stream and phospholipids were re-dissolved in $2 \mathrm{~mL}$ of hexane. Samples were trans-esterified as originally described by Christie (1982), and recently optimized within our laboratory as previously published (Fainberg et al., 2012), as follows: $40 \mu \mathrm{L}$ of methyl acetate was added to the phospholipid samples, which were mixed by vortexing. Then, $40 \mu \mathrm{L}$ of methylation reagent $(0.9 \mathrm{~mL}$ of $30 \%$ sodium methoxide in $4.1 \mathrm{~mL}$ of methanol; Fisher Scientific Ltd.) was added to each sample. The mixture was vortexed and left to stand for $10 \mathrm{~min}$ at room temperature to react, and then $60 \mu \mathrm{L}$ of termination reagent $(0.2 \mathrm{~g}$ of oxalic acid in $6 \mathrm{~mL}$ of diethyl ether) was added, followed once more by vortexing. Then $200 \mathrm{mg}$ of calcium was added and allowed to stand for $1 \mathrm{~h}$ to absorb the moisture. The samples were centrifuged for 5 min at $3,400 \times g$ and the supernatant was transferred to a GC vial, which was now a sample of purified FAME. Two microliters of C19:0 FAME was added to each sample as an internal standard, and this sample was used directly for GC. Triglyceride (TAG) content was assessed using the Folch method (Folch et al., 1957), followed by colorimetric commercial assay (Randox Ltd., County Antrim, UK), and results were expressed in milligrams per gram of tissue dissected.

A total of 37 FAME were analyzed (full list provided in Table 1). This included methyl esters of SFA: C4:0, C6:0, C8:0, C10:0, C11:0, C12:0, C14:0, C15:0, C16:0, C17:0, C18:0, C20:0, C21:0, C22:0, C23:0, and C24:0; MUFA: C14:1, C15:1, C16:1, C17:1, C20:1 and C24:1; and PUFA n-3: C18:3n-3, C20:3n-3, C20:5n-3, and C22: 6n-3; n-6: C18:2n-6 trans, C18:2n-6, C20:3n-6, and C20: 4n-6; and n-9: C18:1n-9 trans, C18:1n-9 cis, and C20:1n -9. Concentrations of each fatty acid were expressed as moles per 100 moles of FAME tested, calculated from the relative areas beneath the peaks at each fatty acid, and also expressed as percentages/proportions of total FAME tested (referred to as percentage).

\section{Statistical Analysis}

Adipocyte size, relative percentages of individual fatty acid types, and SFA, MUFA, PUFA, and mg/gram of tissue TAG were statistically analyzed. Both relative percentages and raw concentrations of fatty acids were analyzed; there were no differences between the statistical outputs for the raw values and percentages. Statistical analysis was also carried out to compare pre-slaughter BCS (in 2 groups 1.50 to 2.50 and 3.00 to 4.00 inclusive and into 3 groups 1.50 to $2.00,2.50$, and 3.00 to 4.00 inclusive), age (2 groups aged 2 to $<4$ yr and $\geq 4$ to $6.5 \mathrm{yr}$ ), claw location (4 groups: right and left medial, and right and left lateral), genetic line (control or select), and dietary regimen (homegrown or by-product).

When the 4 claws were analyzed separately, ANOVA with Tukey pairwise comparison was used for the 4 groups. For all comparisons containing 2 groups including age, BCS, feed regimen, and genetic background, Levene's test for equality of variances followed by $t$ - 


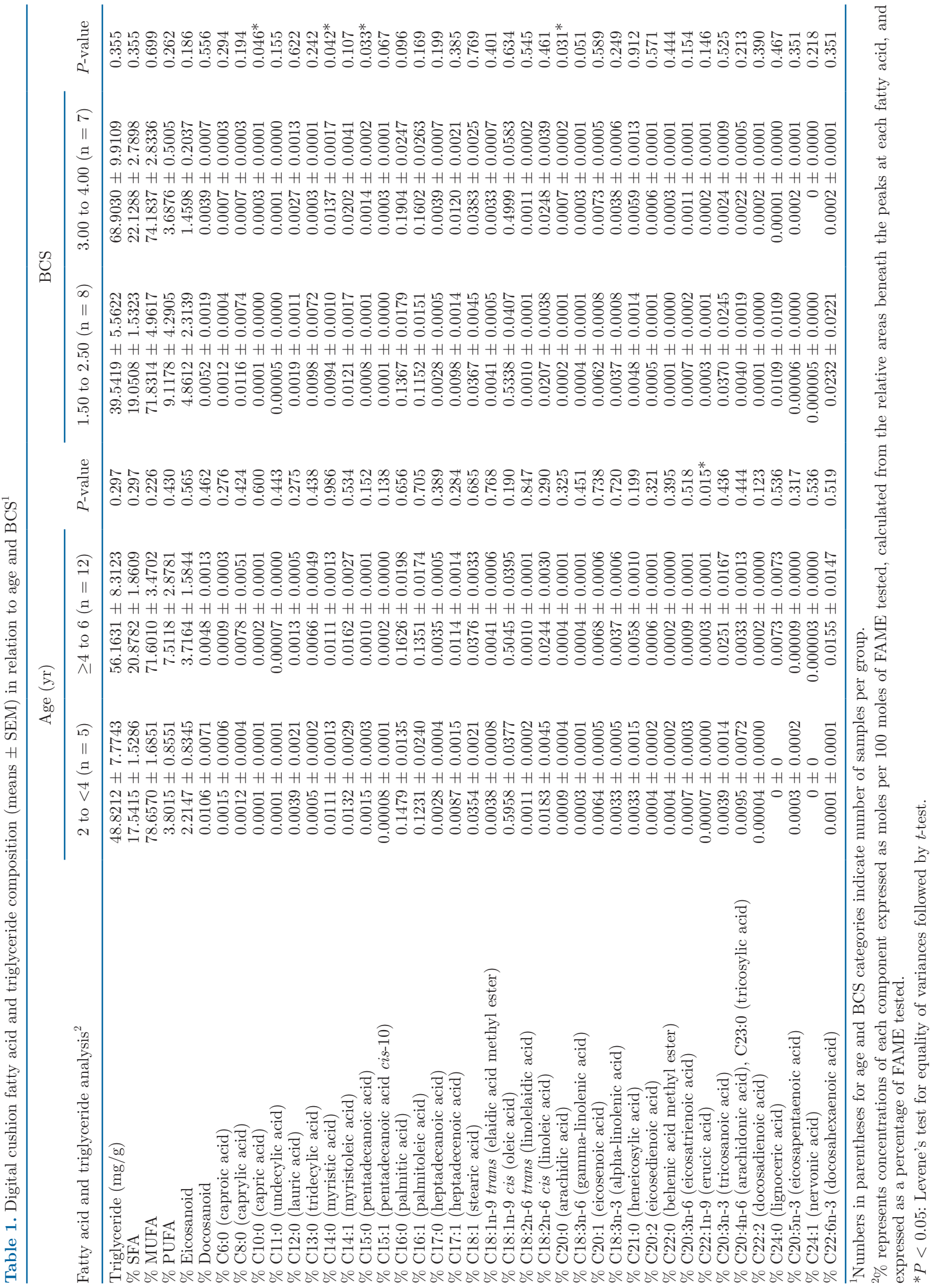


test was used using data from all 4 claws combined as an average per animal (Benjamini and Hochberg false discovery rate corrections were used where applicable). Where applicable, graphical representations were created using Excel (Microsoft).

\section{RESULTS}

\section{Morphological Description of Digital Cushion Tissue Architecture}

The digital cushion is the subcutis tissue layer and was bordered superficially by the reticular layer (Figure $3 \mathrm{~A}$ ) of the dermis, which consisted of dense irregular connective tissue, with densely packed fibers, sparsely populated with nucleated cells that appeared to be fibroblasts. While there was a distinct boundary between the reticular layer of the dermis and the subcutis, projections of dense irregular connective tissue extending from the reticular layer protruded and encompassed regions of the subcutis, such that the classic tissue layers were less distinct (Figure 3B). The subcutis layer consisted primarily of loose connective tissue that, in places, was highly vascularized and interspersed with lobules of unilocular adipocytes (Figure 3C and D). Additionally, dendritic strands of adipose tissue (Figure $3 \mathrm{C})$ ran through the reticular layer in places. Further, the reticular dermis contained channels of loose connective tissue hosting blood vessels extending through it (Figure 3D).

The subcutis tissue was more highly nucleated than the reticular dermis, resembling loose connective tissue and populated with fibroblasts, epithelia, adipocytes, and likely migrants of the immune system from blood vessels. Distinct areas of tissue contained large, unilocular adipocytes, and ran as dendritic projections through the loose connective tissue stroma (Figure 3C). The mature adipocytes consisted of a large vacuole, resembling the triglyceride vacuole and had a thin membrane and an eccentric nucleus. Within these branches, adipocytes sat in lobules surrounded by connective tissue (clearly demonstrated in Figure 3B and C), and a thinner connective tissue stroma connected adipocytes within lobules. These large adipocytes had been the primary focus for the stereology. Vascular tissue ran around and through these projections of adipocytes, visible as dense areas of hematoxylin-stained epithelia, which usually formed concentric circles of approximately $20 \mu \mathrm{m}$ in diameter (Figure 3C, E, F).

There was also another population of cells that were much smaller than the large unilocular adipocytes that occurred in finger-like projections throughout the tissue. These cells occurred diffusely throughout the entire subcutis tissue and were found in the majority of sam- ples. Sometimes they surrounded the finger-like projections of adipocytes, and elsewhere they occurred where no large adipocytes were visible. These were small with cell cross-sectional areas of ranging from 40 to $70 \mu \mathrm{m}^{2}$, with a visible lipid droplet, cell membrane, and nucleus. The nucleus did not sit eccentrically within the cell as with the large adipocytes described earlier; more, it sat just within the membrane, alongside a single lipid droplet. The nucleus was surrounded by a small amount of visible cytoplasm, which was barely visible in large adipocytes. These cells differed from brown adipocytes as they had a single lipid droplet and the nucleus was not central to the cell. These cells resembled large (late) lipoblasts (Figure 3F). Four samples contained no fat cells within any of the 4 histological sections, which were taken a minimum of $240 \mu \mathrm{m}$ apart. In contrast, some digital cushions were predominantly fat, marking stark morphological differences between some specimens.

\section{Adipocyte Morphology and Stereology}

Cell dimensions were based on data from 16 cows: 60 claws, of which 32 were lateral and 28 were medial (the remaining $\mathrm{n}=1$ cow was used for protocol optimization). A total of 11,853 cells were measured; in 6 samples, too few adipocytes were present to reach the cell count of 200 , although $>120$ cells were still counted from each sample. Further, and as mentioned above, some adipocytes were very small and were suspected to belong to different subsets of cells. Other measurements showed disrupted plasma membranes and all measured $>2,000 \mathrm{\mu m}^{2}$; these were not included within the measurements as 2 or more cells would have been measured In total, 419 cells had an average area $<70 \mu \mathrm{m}^{2}$. In addition, 206 measurements had an area $>2,000 \mu \mathrm{m}^{2}$; the average area of this subset was $25,055 \mu \mathrm{m}^{2}$ and predominantly occurred within just 3 tissue samples. Where these apparent outliers were present, they were preferentially not included within the analyzed data as they were suspected to be fibroblastic preadipocytes/ large (late) lipoblasts/adipoblasts (for the smaller cells), or multiple cells together where cell membranes had broken. Ratios of the different classifications of cells therefore in no way represent the relative adipocyte abundance within the tissue.

The final data set compiled from histology that was used for analysis consisted of 11,228 cells and the mean number of adipocytes analyzed per sample was 220 . Cell area followed a chi-squared distribution, with a median of $457 \mu^{2}$ (interquartile range: 265 to 698 ) and cell diameter showed a mean of $24.5 \mu \mathrm{m}$ (SD: 8.0). Mean adipocyte size at slaughter was smaller in cows with a BCS of 1.50 to 2.00 compared with cows that 
had a BCS of 3.00 to $4.00(411.7 \pm 46.5$ vs. $571.3 \pm$ $38.5 \mu^{2}$, respectively; $P=0.044$; Figure $4 \mathrm{~A}$ and $\mathrm{B}$ ); adipocyte size in cows with BCS of 2.50 was intermediate $\left(508.5 \pm 34.9 \mu^{2}\right)$ and did not differ cows from cows with BCS 1.50 to 2.00 or 3.00 to 4.00 (both $P>$ $0.15)$. Cows on the homegrown feed regimen $(\mathrm{n}=11)$ and by-product $(\mathrm{n}=8)$ diet had similar adipocyte cell size $\left(540.8 \pm 31.8\right.$ and $471.4 \pm 32231.0 \mu \mathrm{m}^{2}$, respectively; $P=0.148$; Table 2). No significant differences in size were observed between animals in the 2 age groups $(\mathrm{n}=4$, aged 2 to $<4$, and $\mathrm{n}=14$, aged $\geq 4-6.5 ; 453.37$ \pm 36.21 and $532.35 \pm 27.52 \mu^{2}$, respectively; $P=$ 0.141; Figure 4A), or between animals in the control and select genetic lines $(\mathrm{n}=11$ and 8 , respectively, and area was $545.12 \pm 29.98$ and $465.43 \pm 32.40 \mu \mathrm{m}^{2}$, respectively, $P=0.093$; Table 2 , Figure $4 \mathrm{~A}$ ), or between the 4 locations (left lateral, $518.16 \pm 43.01 \mu^{2}$; left medial, $537.54 \pm 30.06$; right lateral, $540.15 \pm 37.66$; and right medial, $465.45 \pm 42.64$, ANOVA $P=0.535$; Figure 4C).

\section{Fatty Acid Analysis}

Fatty acid analysis was based on data from 17 cows, 55 claws, as some samples were used to optimize protocols. Descriptive data of the fatty acid analysis are
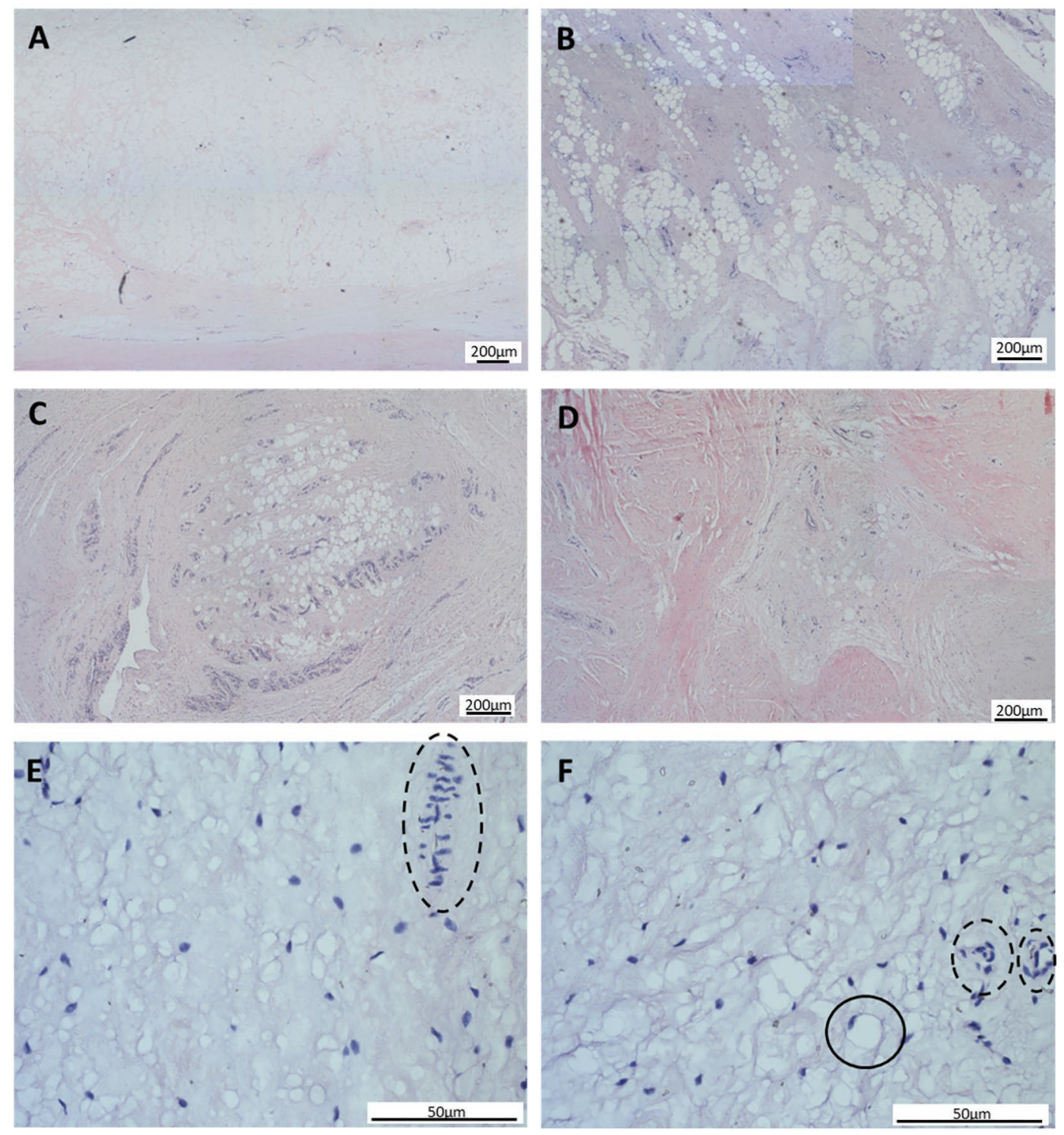

Figure 3. Photomicrographs of showing digital cushion architecture. (A) Reticular layer. (B) Reticular layer of the dermis and the subcutis. $(\mathrm{C}$ and $\mathrm{D})$ The subcutis layer containing loose connective tissue, blood vessels, and lobules of unilocular adipocytes. (E and F) Blood vessels (dotted line) and cells resembling large (late) lipoblasts. Scale bars represent (A-D) $200 \mu \mathrm{m}$, and (E and F) $50 \mu \mathrm{m}$. 
presented in Tables 1 and 2. The proportions of PUFA, MUFA, and SFA were not significantly different in the left or right, lateral or medial claw $(P=0.584,0.556$, and 0.706 , respectively; Figure 5A). When looked at overall, their percentages did not differ between the lower and higher BCS groups $(P=0.430,0.226$, and 0.297 , respectively) or the younger and older cows $(P=$ $0.262,0.699$, and 0.355 , respectively; Table 1 and Figure $5 \mathrm{~B}$ and $\mathrm{C}$ ). In addition, the feed group (homegrown vs. by-product, $P=0.198,0.268,0.870$ for PUFA, MUFA,
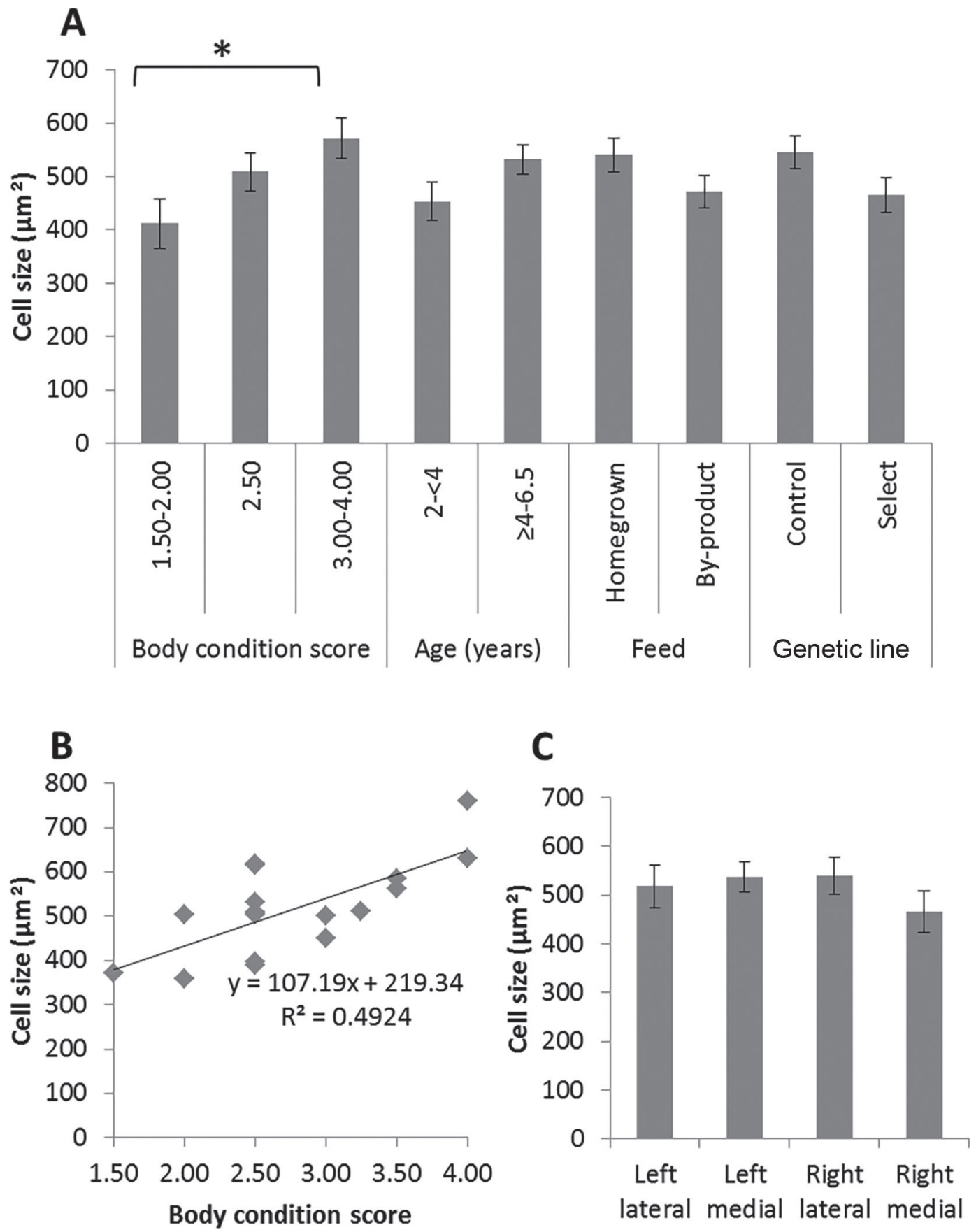

Digital cushion location

Figure 4. Mean adipocyte cell cross-sectional area in the digital cushion. (A) Cows with differing ages, BCS, feed regimens, and genetic lines. (B) Adipocyte area against BCS. (C) Cell size in the left and right lateral, and left and right medial cushions across all cows. Statistical

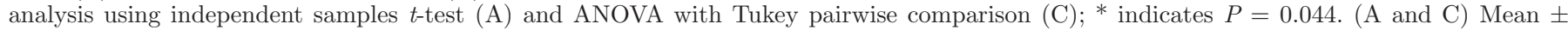
$\mathrm{SEM}$; (B) mean and regression line. 


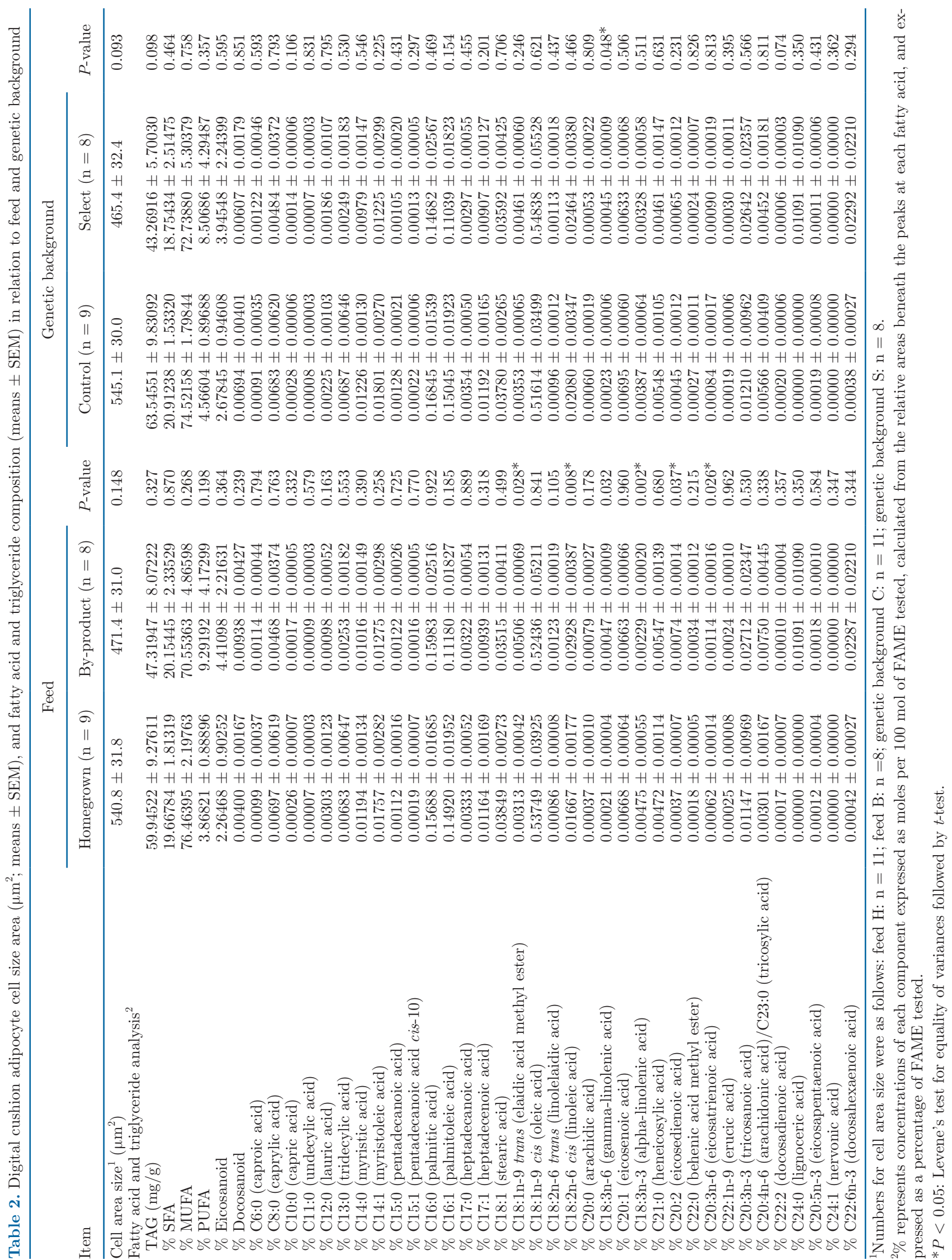



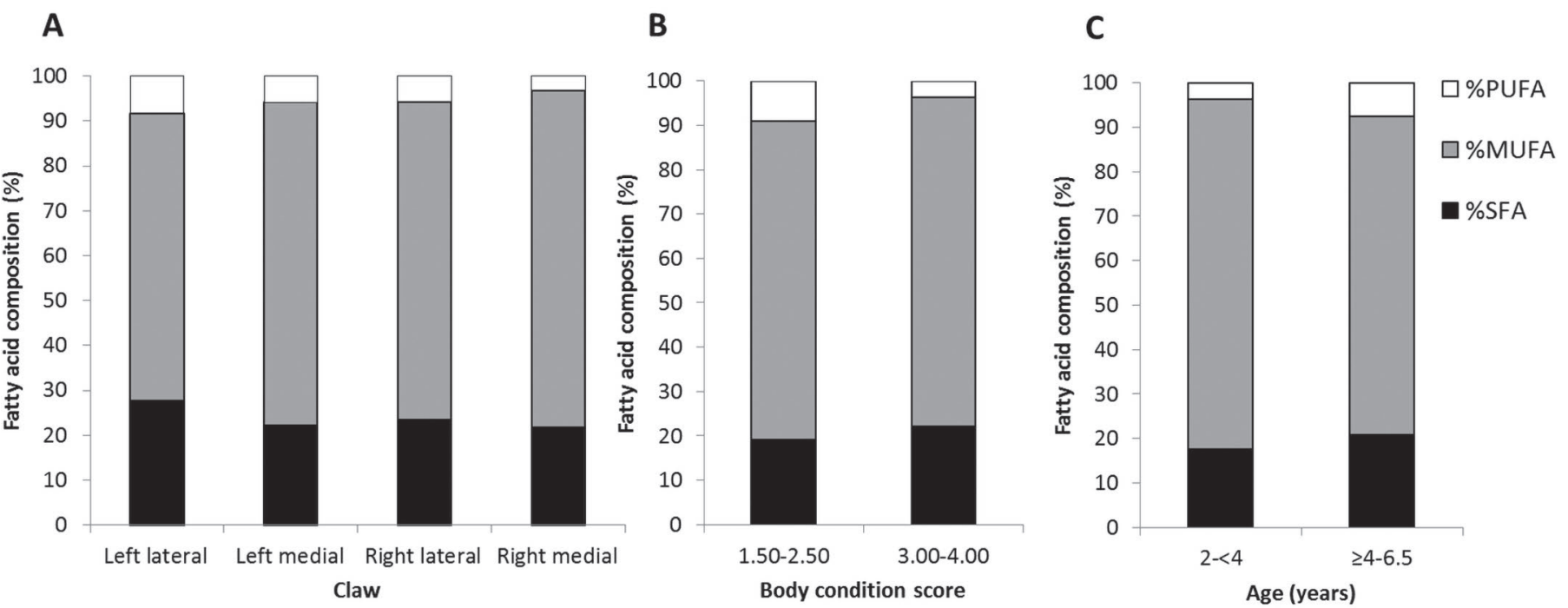

Figure 5. Fatty acid profile within digital cushion. Percentage of PUFA, MUFA, and SFA. (A) Within each claw (n $=17 ; P>0.05$, ANOVA with Tukey). (B) Body condition score grouped into scores of 1.50 to $2.50(\mathrm{n}=8)$ and 3.00 to $4.00(\mathrm{n}=7 ; P>0.05$ independent samples $t$-test). (C) Age grouped into 2 to $<4 \mathrm{yr}(\mathrm{n}=5)$ and $\geq 4$ to $6.5 \mathrm{yr}(\mathrm{n}=12 ; P>0.05$ independent samples $t$-test $)$.

and SFA, respectively) and genetic background showed no significant differences $(P=0.357,0.758$, and 0.464 , respectively; Table 2).

Individual analysis of the 37 FAME showed that 5 of them were significantly different between BCS and age groups. Percentages of C10:0 capric acid $(P=0.046)$, C14:0 myristic acid $(P=0.042)$, C15:0 pentadecanoic acid $(P=0.033)$, and $\mathrm{C} 20: 0$ arachidic acid $(P=$ 0.031 ) were all lesser in cows with a BCS of 1.50 to 2.50 in comparison to those classified as 3.00 to 4.00 immediately before slaughter (Table 1 and Figure 6A). Percentages of C22:1n-9 erucic acid were lesser in the cows aged 2 to $<4$ yr in comparison to those aged $\geq 4$ to $6 \mathrm{yr}$ at slaughter $(P=0.0150$; Figure $6 \mathrm{~B})$. These FAME were not significantly different in the 2 feed groups or genetic backgrounds; however, differences were observed in other FAME. Percentages of C18:1n -9 trans elaidic acid methyl ester $(P=0.028), C 18: 2 \mathrm{n}$ -6 cis linoleic acid $(P=0.008)$, and $\mathrm{C} 18: 3 \mathrm{n}-6$ gammalinolenic acid $(P=0.032)$ were lesser in the homegrown versus by-products, whereas percentages of C18:3n-3 alpha-linolenic acid $(P=0.002), \mathrm{C} 20: 2$ eicosedienoic acid $(P=0.037)$, and $C 20: 3 n-6$ eicosatrienoic acid $(P$ $=0.026)$ were greater in the homegrown feed group (Table 2). The only difference between the control and select genetic background group was a greater percentage of $\mathrm{C} 18: 3 \mathrm{n}-6$ gamma-linolenic acid $(P=0.048)$ in the control group (Table 2).

Analysis of the TAG showed no significant differences between the 4 claws (Figure $7 \mathrm{~A}$ ) or the 2 feed groups or 2 genetic backgrounds (Table 2). The BCS 1.50 to 2.50 group had TAG measurement per gram of tissue $57.39 \%$ lesser than the BCS 3.00 to 4.00 group (Figure 7B; $P=0.019$ ), whereas age did not alter TAG concentrations (Figure 7C; Table 1).

\section{DISCUSSION}

\section{Anatomical and Cellular Structure of the Digital Cushion}

This study provides analysis of the morphology and composition of the digital cushion, the subcutis layer of skin plantar to the distal phalanx, which is considered to be important in dissipating forces during foot strike and enables protection of the germinal epithelium. The work highlighted that there are differing subgroups of digital cushion adipocytes and that they form fingerlike projections throughout the tissue rather than being present throughout the entire cushion structure. A previous preliminary report (Räber et al., 2006) showed that lipid content differed in various regions of the fat pad; this may, in part, be due to the projections of fat observed in our study, as the fat was not heterogeneous throughout the tissue.

This study found that adipocyte cell size was significantly larger in animals with a higher BCS. This is consistent with a previous study that investigated adipocyte size in bovine right front claws in cows with a BCS of less than 3.00, and 3.00 or more, on a 1 to 5 scale (Hiss-Pesch et al., 2019), a study which also supports our assertion that the digital cushion is not a homogeneous tissue. Interestingly, the average adipocyte cell size in the current study (between 373 and 

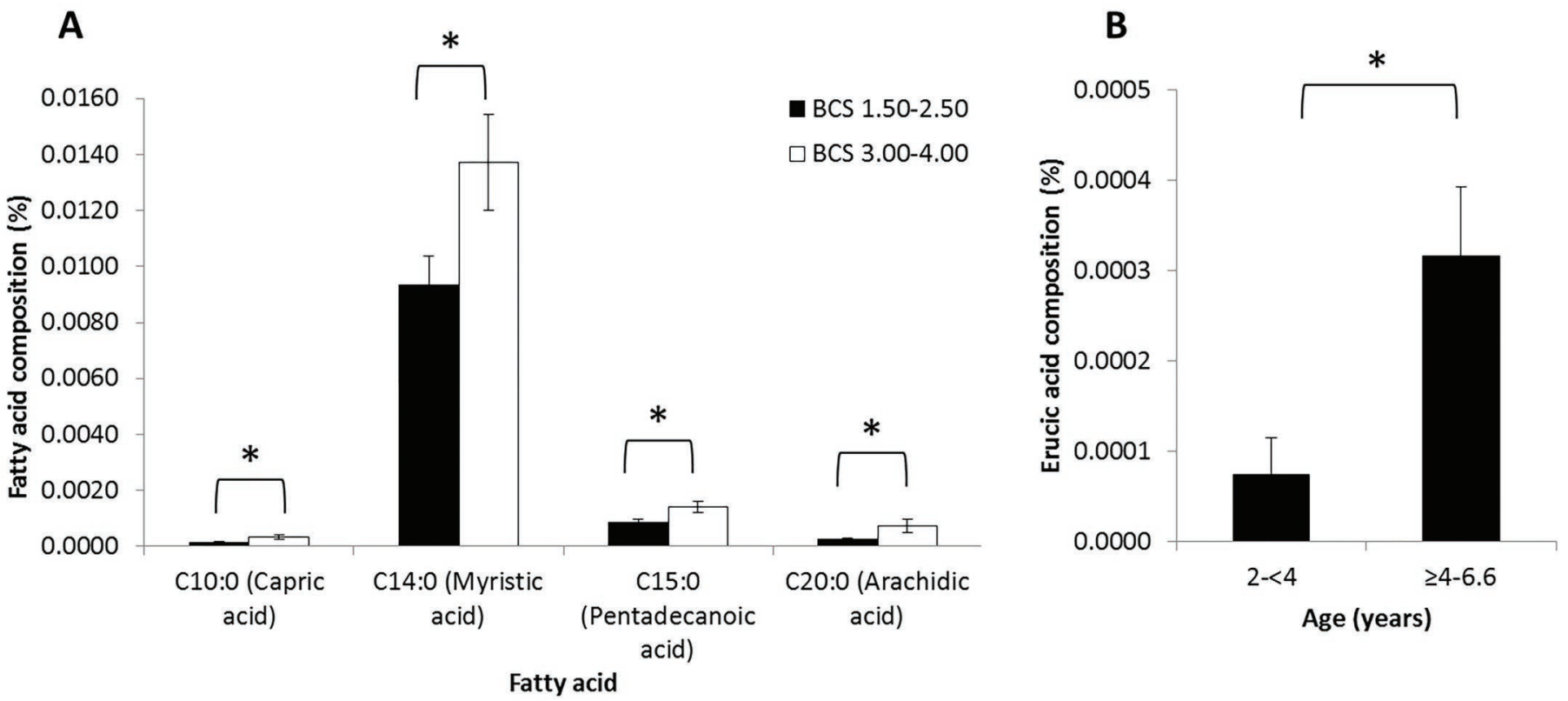

Figure 6. Fatty acid composition. (A) Percentages of C10:0 capric acid $(P=0.0460)$; C14:0 myristic acid $(P=0.0420)$; C15:0 pentadecanoic acid $(P=0.0330)$; C20:0 arachidic acid $(P=0.0310)$; for cattle with BCS of 1.50 to $2.50(\mathrm{n}=8)$ and 3.00 to $4.00(\mathrm{n}=7)$. (B) Percentages of C22:1n-9 erucic acid $(P=0.0150)$ in cows aged 2 to $<4(\mathrm{n}=5)$ and $\geq 4-6$ yr $(\mathrm{n}=12)$. Analysis used independent samples $t$-test; $*$ indicates $P$ $<0.05$. Mean of each fatty acid from the total sum of fatty acids \pm SEM.

$759 \mu^{2}$ for each individual animal), was smaller in comparison to other publications on bovine species, where digital cushion adipocyte averages were between 1,426 and 5,692 $\mu^{2}$ depending on the breed, location of the sample, and factors such as BCS (HissPesch et al., 2019). Adipocytes in subcutaneous and retroperitoneal adipose tissues reached around 7,000 and $8,000 \mu \mathrm{m}^{2}$ (Kénéz et al., 2015), whereas another study showed that subcutaneous and visceral depots had adipocyte cell areas ranging from 4,521 to 7,945 $\mu \mathrm{m}^{2}$ (Akter et al., 2011). These results highlight the unique attributes of differing depots both throughout the entire body and within the differing areas of the digital cushions. The differences in our adipocyte cell sizes based around BCS may also at least partly explain the link between reduced BCS and lameness risk, if larger adipocytes provide better force dissipation and thus better protect the germinal epithelium from contu-
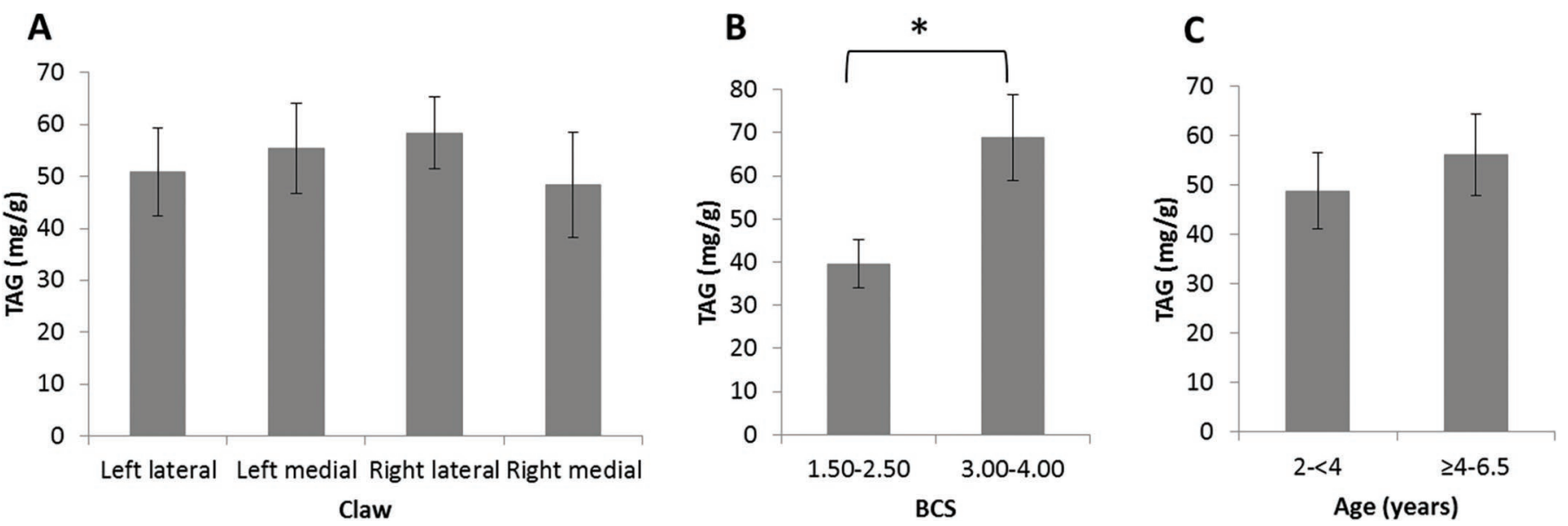

Figure 7. Triglyceride (TAG) within digital cushions. (A) Within each individual claw in all samples $(\mathrm{n}=17 ; P>0.05$, ANOVA with Tukey). (B) Body condition score grouped into scores of 1.50 to $2.50(\mathrm{n}=8)$ and 3.00 to $4.00\left(\mathrm{n}=7\right.$; ${ }^{*} P=0.019$, independent samples $t$-test). (C) Age grouped into 2 to $<4$ yr $(\mathrm{n}=5)$ and $\geq 4$ to 6 yr $(\mathrm{n}=12 ; P>0.05$, independent samples $t$-test $)$. 
sion. The reverse scenario may also be a complication, whereby lameness may lead to a loss of body condition and associated reductions in adipocyte sizes, which could in itself could result in differing force dissipation. Further, higher producing cows in early lactation are more likely to go lame, which can subsequently lead to a drop in milk production (Bicalho et al., 2009; Bicalho and Oikonomou, 2013). It is therefore possible that the mobilization of fat in dairy cows with high milk yields is unrestricted to fat depots that are principally energy stores, and that they mobilize fat from functional fat reserves such as the digital cushion, at the expense of their own health.

Subjective assessments of fat content have previously indicated that the medial claw of the hind limb contained more fat than the lateral claw (Räber et al., 2004, 2006). Our study found differences in adipocyte cell size in differing BCS, but no differences between cell size in the differing claws. Adipose tissue mass can expand by 1 of 2 methods: hyperplasia, which increases cell number, and hypertrophy, an increase in cell size. Therefore, it is possible that overall differing digital cushion sizes in the 4 limbs observed by others may be due to hyperplasia, possibly in conjunction with smaller changes in hypertrophy.

Several pieces of work that have used ultrasonography to assess the digital cushions of live cows demonstrate that sole soft tissues alter throughout lactation, and Räber et al. (2006) reported that digital cushions of heifers and cows have differing fatty acid compositions. In the future it would be of value to understand whether the digital cushion changes structure and composition under differing conditions such as age, lactation, sex, and during pregnancy as this may have an influence on the development of CHDL.

Site E was chosen to study the morphology of the digital cushion since the hypothesized function of the cushion is to dissipate forces away from the germinal epithelium, and therefore morphology in this area may be more relevant to its function. This site had a higher proportion of connective tissue than those plantar to the tuberculum flexorium, as shown by Räber et al. (2006), making lipid extraction much more difficult as the sample must be homogenized. Further, the amount of lipid available at site E after extraction was typically less than the required amount for the fatty acid analysis techniques used. Site B had depots of lipid with much lower proportions of connective tissue, perhaps as the physical structure is less pertinent to function, and therefore lipid extraction was more robust and reliable. The morphology performed in this work was therefore not intended to be a comprehensive catalog of all areas of the digital cushion in all different pathologies. It describes morphology of the digital cushion in an area that appears to be most functionally important. The descriptions are valuable as the first such morphological description of the digital cushion.

\section{Fatty Acid Percentages in the Digital Cushion}

Our study is the first to show measurements of 37 individual fatty acids and overall SFA, PUFA, and MUFA percentages in the bovine digital cushion with comparisons made between different ages, BCS, and the medial and lateral claws on the 2 hindlimbs. No differences in overall SFA, PUFA, or MUFA percentages were found in the digital cushions based on location of the claw or age, although the study was limited to those aged 2 to 6 yr with samples from 55 claws. Preliminary work has suggested greater SFA percentages in younger animals (Räber et al., 2006), perhaps because the tissue is immature. However, their statistical analysis did not account for repeated measures of the same animals as each claw was treated as independent, which was corrected for in this work; therefore, this remains an area for future work. Our work also showed no overall differences in SFA, PUFA, or MUFA based on BCS, positioning of the claw (medial or lateral), genetic line, or feed management system. On average our Holstein/ Friesian cows had $70.4 \%$ MUFA content, which was less than the $79.5 \%$ observed in a preliminary report on Brown Swiss cows in areas taken from the same anatomical location within the digital cushion (Räber et al., 2006). Our cattle also showed $23.8 \%$ SFA and $5.8 \%$ PUFA on average in comparison to $16.2 \%$ and $4.3 \%$, respectively, in the previous publication. These differences may be attributable to feed, age, or breed differences between the 2 cohorts but may also be due to the heterogeneous nature of the fat depots themselves within the digital cushion. The previous study highlighted significant differences in SFA, MUFA, and PUFA quantities throughout the digital cushion.

The percentages of C10:0 capric acid, C14:0 myristic acid, C15:0 pentadecanoic acid, and C20:0 arachidic acid were all lesser in cows with a lower BCS but did not differ due to age, feed regimen, or genetic background, their relative percentages in the digital cushion have never been reported before. C10:0 capric acid is a SFA often associated with coconut and palm kernel oil and constitutes around 1.19 to $2.01 \%$ of total fatty acid content in cow milk (Beare-Rogers et al., 2001) and is present in raw beef. Capric acid is also a medium-chain fatty acid and can be broken down quickly and transported to the liver as an immediate energy source or utilized as ketones. Therefore, it may be possible that cows losing body condition use capric acid as an energy source at a higher rate than other portions of the digital cushion; however, given the relatively low abundance of 
this fatty acid this may not produce an abundance of energy or ketones. C14:0 myristic acid (Beare-Rogers et al., 2001) is also found in palm kernel and coconut oil and constitutes 8 to $14 \%$ of bovine milk. It is a saturated fat and has been linked to increased serum cholesterol and cardiovascular disease in people (German and Dillard, 2010). Increased dietary myristic acid in Holsteins has been linked to increased concentrations in the milk but also inhibition of methane production (Odongo et al., 2007), C20:0 arachidic acid is also known as eicosanoic acid and it is also a SFA found in corn and peanut oils and bovine milk (Gaspardo et al., 2010). It is also known to be present in differing amounts in bovine tissues such as muscle and kidney adipose tissue (Liu et al., 2015). C15:0 pentadecanoic acid is a long-chain fatty acid that is present in bovine milk at quantities of around $1.2 \%$ due to bacterial production; it also exists naturally in other bacteria, fungi, and some plant oils. In people, higher quantities are associated with lower risk of cardiovascular disease and reduced morbidity (Venn-Watson et al., 2020).

Our data showed that percentages of $\mathrm{C} 22: 1 \mathrm{n}-9$ erucic acid in the digital cushions were lesser in the younger cattle. Erucic acid is a MUFA, common in Brassicaceae plants, especially rapeseed and mustard. It is possible that diet influences composition of the digital cushion, which could explain the difference in younger animals if these animals had been fed different substrates. A study looking at high-erucic acid, low-glucosinolate rapeseed rations indicated that milk yield was lower but feed efficiency increased and milk fat was similarly increased (Hristov et al., 2011). Little work on age and fatty acid composition of the digital cushion has been published. Previous digital cushion work on heifers and cows with average ages 2.3 and $8 \mathrm{yr}$ showed half the quantity of arachidonic acid (C20:4n-6) in the older cows (Räber et al., 2006). The study did not show differences in erucic acid but only mentioned arachidonic acid specifically by name, but overall MUFA, PUFA, and SFA values were given.

Anatomical challenge may also influence the structure of the digital cushion. For example, increased exercise between 2 and 6 mo of age on more challenging surfaces led to a $37 \%$ increase in the volume of the digital cushion at 6 mo of age (Gard et al., 2015); this difference was far greater than percentage differences in digital cushion fatty acid composition reported as a result of other effects (Räber et al., 2006; Baird et al., 2010). Our previous work demonstrated another potential anatomical challenge in the form of increased new bone growth (bone spurs/exostoses) via bone remodeling on the flexor tuberosity of the distal phalanx in animals that had more episodes of CHDL and lameness (Newsome et al., 2016). It is possible that this irregularly shaped bone could damage the digital cushion or affect force dissipation through the tissue, potentially altering the cellular components of the cushion. Lameness incidence was not assessed in the present study and we cannot assess what effect this may have had, but this work contributes to the idea that the digital cushion may differ greatly depending on lameness, diet, and anatomical challenges, in addition to factors such as genetics, lactation stage, housing conditions, BCS, and age. Larger studies that can accommodate multivariate analysis of such variables would benefit this field of research.

\section{CONCLUSIONS}

Our study describes the basic histological structure of the digital cushion and found an effect of BCS on adipocyte size. Additionally some fatty acids in the digital cushion itself were present in differing percentages depending or age, BCS, feed regimen, and genetic background. This suggests that the digital cushion is not only essential in dissipating forces on the limb but also in deposition and release of fat. Whether the fatty acids mobilized from the digital cushion are deposited around the body or into the milk, or both, is still unknown. Fat deposition, mobilization, and composition differences are key components of a healthy animal and may play important roles in milk quality and yield and other health conditions. The digital cushion anatomy, cellular morphology, and fatty acid compositions were altered in animals with differing BCS and ages, in addition to differing feed types and genetic backgrounds, and may play vital roles in cattle health and disorders.

\section{ACKNOWLEDGMENTS}

We thank Dongfang Li, School of Biosciences, for providing the fatty acid composition service and staff at the SRUC Dairy Research and Innovation Centre for sample and animal data collection. This work was supported by the Agriculture and Horticulture Development Board (AHDB; Kenilworth, UK) Dairy Division, a levy board, not-for-profit organization working on behalf of British Dairy Farmers. The Hounsfield Facility was supported by ERC [FUTUREROOTS; Brussels, Belgium (grant agreement ID: 294729)], BBSRC (Swindon, UK), and The Wolfson Foundation (London, UK). The SRUC was supported by the Scottish Government (Edinburgh, UK). This work was supported by the Biotechnology and Biological Sciences Research Council (grant number BB/I024291/1). The funders did not play any roles in design, analysis, or reporting of this study. The authors declare no conflicts of interest. 


\section{REFERENCES}

Akter, S. H., S. Haussler, S. Danicke, U. Muller, D. von Soosten, J. Rehage, and H. Sauerwein. 2011. Physiological and conjugated linoleic acid-induced changes of adipocyte size in different fat depots of dairy cows during early lactation. J. Dairy Sci. 94:2871-2882. https://doi.org/10.3168/jds.2010-3868.

Baird, L. G., L. E. R. Dawson, I. S. Young, and N. E. O'Connell. 2010. Lipid content and fatty acid composition of the digital cushion of bulls offered different amounts of linseed. J. Anim. Sci. 88:24032409. https://doi.org/10.2527/jas.2009-1972.

Beare-Rogers, J. L., A. Dieffenbacher, and J. V. Holm. 2001. Lexicon of lipid nutrition (IUPAC Technical Report). Pure Appl. Chem. 73:685-744. https://doi.org/10.1351/pac200173040685.

Bicalho, R. C., V. S. Machado, and L. S. Caixeta. 2009. Lameness in dairy cattle: A debilitating disease or a disease of debilitated cattle? A cross-sectional study of lameness prevalence and thickness of the digital cushion. J. Dairy Sci. 92:3175-3184. https://doi .org/10.3168/jds.2008-1827.

Bicalho, R. C., and G. Oikonomou. 2013. Control and prevention of lameness associated with claw lesions in dairy cows. Livest. Sci. 156:96-105. https://doi.org/10.1016/j.livsci.2013.06.007.

Björnheden, T., B. Jakubowicz, M. Levin, B. Oden, S. Eden, L. Sjostrom, and M. Lonn. 2004. Computerized determination of adipocyte size. Obes. Res. 12:95-105. https://doi.org/10.1038/oby.2004 .13 .

Casutt, M. M., M. R. L. Scheeder, F. Escher, P. Dufey, and M. Kreuzer. 1999. Relating texture properties and composition of bovine fat tissue. Eur. J. Lipid Sci. Technol. 101:283-290. https: / / doi.org/10.1002/(SICI)1521-4133(199908)101:8<283::AIDLIPI283>3.0.CO $: 2-O$.

Christie, W. W. 1982. A simple procedure for rapid transmethylation of glycerolipids and cholesteryl esters. J. Lipid Res. 23:1072-1075. https://doi.org/10.1016/S0022-2275(20)38081-0.

Dietz, O., and H. Heyden. 1990. Zur Entstehung der Sohlenlederhautquetschung beim Rind. Monatsh. Veterinarmed. 45:14-17.

Fainberg, H. P., K. Bodley, J. Bacardit, D. Li, F. Wessely, N. P. Mongan, M. E. Symonds, L. Clarke, and A. Mostyn. 2012. Reduced neonatal mortality in Meishan piglets: A role for hepatic fatty acids? PLoS One 7:e49101. https://doi.org/10.1371/journal.pone .0049101

Folch, J., M. Lees, and G. H. Sloane Stanley. 1957. A simple method for the isolation and purification of total lipides from animal tissues. J. Biol. Chem. 226:497-509. https://doi.org/10.1016/S0021 $-9258(18) 64849-5$

Gard, J. A., D. R. Taylor, D. R. Wilhite, S. P. Rodning, M. L. Schnuelle, R. K. Sanders, R. J. Beyers, M. A. Edmondson, F. J. DeGraves, and E. van Santen. 2015. Effect of exercise and environmental terrain on development of the digital cushion and bony structures of the bovine foot. Am. J. Vet. Res. 76:246-252. https:/ /doi.org/10.2460/ajvr.76.3.246.

Gaspardo, B., A. Lavrencic, A. Levart, S. Del Zotto, and B. Stefanon. 2010. Use of milk fatty acids composition to discriminate area of origin of bulk milk. J. Dairy Sci. 93:3417-3426. https://doi.org/10 $.3168 / \mathrm{jds} .2009-2788$.

German, J. B., and C. J. Dillard. 2010. Saturated fats: A perspective from lactation and milk composition. Lipids 45:915-923. https:// doi.org/10.1007/s11745-010-3445-9.

Green, L. E., J. N. Huxley, C. Banks, and M. J. Green. 2014. Temporal associations between low body condition, lameness and milk yield in a UK dairy herd. Prev. Vet. Med. 113:63-71.

Hiss-Pesch, S., J. Weise, B. Heitkonig, and H. Sauerwein. 2019. Short communication: Adipocyte sizes in the digital fat pad and their relationship to body condition in dairy cows. J. Dairy Sci. 102:65516554. https://doi.org/10.3168/jds.2018-15531.

Hristov, A. N., C. Domitrovich, A. Wachter, T. Cassidy, C. Lee, K. J. Shingfield, P. Kairenius, J. Davis, and J. Brown. 2011. Effect of replacing solvent-extracted canola meal with high-oil traditional canola, high-oleic acid canola, or high-erucic acid rapeseed meals on rumen fermentation, digestibility, milk production, and milk fatty acid composition in lactating dairy cows. J. Dairy Sci. 94:4057-4074. https://doi.org/10.3168/jds.2011-4283.

Keane, M., E. Paul, C. J. Sturrock, C. Rauch, and C. S. Rutland. 2016. Computed tomography in veterinary medicine: Currently published and tomorrow's vision. Pages 271-289 in Computed Tomography-Advanced Applications. A. M. Halefoglu, ed. InTechOpen.

Kénéz, A., A. Kulcsar, F. Kluge, I. Benbelkacem, K. Hansen, L. Locher, U. Meyer, J. Rehage, S. Danicke, and K. Huber. 2015. Changes of adipose tissue morphology and composition during late pregnancy and early lactation in dairy cows. PLoS One 10:e0127208. https:/ /doi.org/10.1371/journal.pone.0127208.

Lim, P. Y., J. N. Huxley, J. A. Willshire, M. J. Green, A. R. Othman, and J. Kaler. 2015. Unravelling the temporal association between lameness and body condition score in dairy cattle using a multistate modelling approach. Prev. Vet. Med. 118:370-377.

Lischer, C. J., P. Ossent, M. Räber, and H. Geyer. 2002. Suspensory structures and supporting tissues of the third phalanx of cows and their relevance to the development of typical sole ulcers (Rusterholz ulcers). Vet. Rec. 151:694-698.

Liu, T., Z. M. Lei, J. P. Wu, and M. A. Brown. 2015. Fatty acid composition differences between adipose depot sites in dairy and beef steer breeds. J. Food Sci. Technol. 52:1656-1662. https://doi.org/ 10.1007/s13197-013-1117-5.

Machado, V. S., L. S. Caixeta, and R. C. Bicalho. 2011. Use of data collected at cessation of lactation to predict incidence of sole ulcers and white line disease during the subsequent lactation in dairy cows. Am. J. Vet. Res. 72:1338-1343.

Mayhew, T. M., and G. J. Burton. 1988. Methodological problems in placental morphometry: Apologia for the use of stereology based on sound sampling practice. Placenta 9:565-581. https://doi.org/ 10.1016/0143-4004(88)90001-X.

Mulvany, P. M. 1977. A body condition scoring technique for use with British Friesian cows. Anim. Prod. 24:157-158.

Newsome, R., M. J. Green, N. J. Bell, M. G. G. Chagunda, C. S. Mason, C. S. Rutland, C. J. Sturrock, H. R. Whay, and J. N. Huxley. 2016. Linking bone development on the caudal aspect of the distal phalanx with lameness during life. J. Dairy Sci. 99:4512-4525. https://doi.org/10.3168/jds.2015-10202.

Newsome, R. F., M. J. Green, N. J. Bell, N. J. Bollard, C. S. Mason, H. R. Whay, and J. N. Huxley. 2017a. A prospective cohort study of digital cushion and corium thickness. Part 1: Associations with body condition, lesion incidence, and proximity to calving. J. Dairy Sci. 100:4745-4758. https://doi.org/10.3168/jds.2016-12012.

Newsome, R. F., M. J. Green, N. J. Bell, N. J. Bollard, C. S. Mason, H. R. Whay, and J. N. Huxley. 2017b. A prospective cohort study of digital cushion and corium thickness. Part 2: Does thinning of the digital cushion and corium lead to lameness and claw horn disruption lesions? J. Dairy Sci. 100:4759-4771. https://doi.org/ $10.3168 /$ jds.2016-12013.

Odongo, N. E., M. M. Or-Rashid, E. Kebreab, J. France, and B. W. McBride. 2007. Effect of supplementing myristic acid in dairy cow rations on ruminal methanogenesis and fatty acid profile in milk. J. Dairy Sci. 90:1851-1858. https://doi.org/10.3168/jds.2006-541.

Osman, O. S., J. L. Selway, M. A. Kepczynska, C. J. Stocker, J. F. O'Dowd, M. A. Cawthorne, J. R. Arch, S. Jassim, and K. Langlands. 2013. A novel automated image analysis method for accurate adipocyte quantification. Adipocyte 2:160-164. https://doi .org/10.4161/adip.24652.

Parlee, S. D., S. I. Lentz, H. Mori, and O. A. MacDougald. 2014. Quantifying size and number of adipocytes in adipose tissue. Methods Enzymol. 537:93-122. https://doi.org/10.1016/B978-0 -12-411619-1.00006-9.

Pryce, J. E., B. L. Nielsen, R. F. Veerkamp, and G. Simm. 1999. Genotype and feeding system effects and interactions for health and fertility traits in dairy cattle. Livest. Prod. Sci. 57:193-201. https: //doi.org/10.1016/S0301-6226(98)00180-8.

Räber, M., C. J. Lischer, H. Geyer, and P. Ossent. 2004. The bovine digital cushion-A descriptive anatomical study. Vet. J. 167:258 264. https://doi.org/10.1016/S1090-0233(03)00053-4. 
Räber, M., M. R. L. Scheeder, P. Ossent, C. J. Lischer, and H. Geyer. 2006. The content and composition of lipids in the digital cushion of the bovine claw with respect to age and location-a preliminary report. Vet. J. 172:173-177. https://doi.org/10.1016/j.tvjl.2005.03 .009 .

Randall, L. V., M. J. Green, M. G. Chagunda, C. Mason, S. C. Archer, L. E. Green, and J. N. Huxley. 2015. Low body condition predisposes cattle to lameness: An 8-year study of one dairy herd. J. Dairy Sci. 98:3766-3777.

Stambuk, C. R., E. A. Staiger, B. J. Heins, and H. J. Huson. 2020. Exploring physiological and genetic variation of digital cushion thickness in Holstein and Jersey cows and bulls. J. Dairy Sci. 103:9177-9194. https://doi.org/10.3168/jds.2020-18290.

Venn-Watson, S., R. Lumpkin, and E. A. Dennis. 2020. Efficacy of dietary odd-chain saturated fatty acid pentadecanoic acid parallels broad associated health benefits in humans: Could it be essential? Sci. Rep. 10:8161. https://doi.org/10.1038/s41598-020-64960-y.

\section{ORCIDS}

R. F. Newsome ㄴ https://orcid.org/0000-0001-5886-0351

A. Mostyn (1) https://orcid.org/0000-0003-3474-289X

N. Bollard ๑ https://orcid.org/0000-0002-1002-9726

M. G. G. Chagunda ํㅣ https://orcid.org/0000-0002-7245-236X

M. Keane $\odot$ https://orcid.org/0000-0001-7453-365X

M. Green (๑ https://orcid.org/0000-0002-6408-6443

J. N. Huxley @ https://orcid.org/0000-0002-1149-2480

C. S. Rutland (1) https://orcid.org/0000-0002-2009-4898 